\title{
A Simple Method Based on NMR and Ultramicroelectrode \\ Voltammetry for the Determination of the Number of Electrons in a
}

Faradaic Process

\author{
Hao Sun and Angel E. Kaifer* \\ Center for Supramolecular Chemistry and Department of Chemistry, University of \\ Miami, Coral Gables, FL 33124-0431
}

\section{SUPPORTING INFORMATION}

Synthesis of tris(ferroceneylmethyl)amine (2). Solid ammonium acetate $(7.7 \mathrm{~g}$, $0.1 \mathrm{~mol})$ was added to a cooled solution $\left(0^{\circ} \mathrm{C}\right)$ of ferrocenecarboxaldehyde $(2.14 \mathrm{~g}$, $10 \mathrm{mmol}$ ) in dry methanol (Aldrich) $(100 \mathrm{~mL}$ ), and stirred for $30 \mathrm{~min}$. Sodium cyanoborohydride $(0.44 \mathrm{~g}, 7 \mathrm{mmol})$ was added to the cool solution. After stirring overnight at room temperature, the volume of the solution was reduced to about $20 \mathrm{~mL}$, and $10 \mathrm{~mL}$ of water was added. The $\mathrm{pH}$ of the solution was adjusted with $1 \mathrm{~N} \mathrm{HCl}$ to $\mathrm{pH}$ 2. Then solid $\mathrm{KOH}$ was added until $\mathrm{pH}$ reached 8 . The resulting dark brown solution with some solid was extracted with $\mathrm{CH}_{2} \mathrm{Cl}_{2}(4 \times 50)$. The organic phase was collected, washed with water, and dried over $\mathrm{MgSO}_{4}$. After filtration the solvent was removed to yield the crude brown oil product, which was further purified by column chromatography $\left(\mathrm{SiO}_{2}, 5 \%\right.$ methanol in $\left.1: 1 \mathrm{CHCl}_{3} / \mathrm{EtOAc}, \mathrm{v} / \mathrm{v}\right)$. The product with $\mathrm{R}_{\mathrm{f}} 0.6$ was collected. Orange needle crystals were obtained $(0.615 \mathrm{~g}, 30 \%)$ after recrystallization from a mixture of hexane and chloroform. ${ }^{1} \mathrm{H}$ NMR $\left(\mathrm{CDCl}_{3}\right): \delta=4.29\left(\mathrm{t}, 6 \mathrm{H} ; \mathrm{C}_{5} \mathrm{H}_{4}\right), 4.14(\mathrm{t}, 6 \mathrm{H}$; $\left.\mathrm{C}_{5} \mathrm{H}_{4}\right), 4.07$ (s, $\left.15 \mathrm{H} ; \mathrm{C}_{5} \mathrm{H}_{5}\right), 3.37$ (s, $\left.6 \mathrm{H} ; \mathrm{CH}_{2}\right)$, ppm; ${ }^{13} \mathrm{C} \mathrm{NMR}\left(\mathrm{CDCl}_{3}\right): \delta=72.17,69.01$, 68.25, 66.76, 56.65, ppm; MS (FAB): $612.0(\mathrm{M}+\mathrm{H})^{+}$ 


\section{X-ray crystal structure of compound 2}

Single crystals of compound $\mathbf{2}$ suitable for X-ray analysis were obtained by slow diffusion of hexane vapor into chloroform solutions of the compound. Diffraction data were collected at $300 \mathrm{~K}$ on a Bruker SMART1000 CCD-based X-ray diffractometer equipped with a Mo-target $X$-ray tube $(\lambda=0.71073 \AA)$. Data were measured using $\omega$ scans of $0.3^{\circ}$ per frame during $10 \mathrm{~s}$ such that a hemisphere was collected. No decay was detected for either one of two data sets collected, as indicated by the re-collection of the first 50 frames at the end of each data acquisition. The frames were integrated with the Bruker SAINT software package using a narrow-frame integration algorithm, which also corrects for Lorentz and polarization effect. Absorption corrections were applied using SADABS supplied by George Sheldrick.

The structure was solved using the Bruker SHELXTL software package version 5.1. The space group was unambiguously assigned as $P 2_{1} / C$. The structure of 2 was refined to convergence by the least-squares method on $F^{2}$, SHELXL-93, incorporated in SHELXTL.PC V5.03, with all non-hydrogen atoms being anisotropic and all hydrogen atoms in calculated position and riding mode. The final least-squares refinements converged at the R-factors reported in Table S1, along with other procedural parameters. 


\section{Table S1. Crystal Data and Structure Refinement for Compound 2}

Empirical formula

Formula weight

Temperature

Wavelength

Crystal system

Space group

Unit cell dimensions

Volume

Z

Density (calculated)

Absorption coefficient

$\mathrm{F}(000)$

Crystal size

Theta range for data collection

Index ranges

Reflections collected

Independent reflections

Refinement method

Data / restraints / parameters

Goodness-of-fit on $F^{2}$

Final $\mathrm{R}$ indices [l>2sigma(I)]

$R$ indices (all data)

Largest diff. peak and hole
C33 H33 Fe3 N

611.15

$300(2) \mathrm{K}$

$0.71073 \AA$

Monoclinic

$\mathrm{P} 2(1) / \mathrm{c}$

$a=10.2333(6) \AA$

$\mathrm{b}=10.0512(6) \AA$

$c=26.7733(16) \AA$

$\alpha=90^{\circ}$

$\beta=99.8330(10)^{\circ}$

$\gamma=90^{\circ}$

2713.4(3) $\AA^{3}$

4

$1.496 \mathrm{Mg} / \mathrm{m}^{3}$

$1.605 \mathrm{~mm}^{-1}$

1264

$0.16 \times 0.16 \times 0.05 \mathrm{~mm}^{3}$

1.54 to $23.28^{\circ}$.

$-11<=\mathrm{h}<=10,-7<=\mathrm{k}<=11,-29<=\mathrm{l}<=26$

12105

$3899[\mathrm{R}(\mathrm{int})=0.0397]$

Full-matrix least-squares on $\mathrm{F}^{2}$

3899 / 0 / 334

1.020

$\mathrm{R} 1=0.0360, w R 2=0.0777$

$\mathrm{R} 1=0.0602, \mathrm{wR} 2=0.0846$

0.397 and -0.290 e. $\AA^{-3}$ 
The resulting molecular structure is shown as ORTEP plots in Figure 2 in the main body of the paper. Selected bond lengths and angles are given in Table S2. In compound 2, the $N(1)-C(1), N(1)-C(12)$ and $N(1)-C(23)$ bond lengths are identical within experimental error. In addition, nitrogen bond angles, for example, the $\mathrm{C}(12)-\mathrm{N}(1)-\mathrm{C}(1), \mathrm{C}(23)-\mathrm{N}(1)-$ $\mathrm{C}(1)$ and $\mathrm{C}(23)-\mathrm{N}(1)-\mathrm{C}(12)$ are identical too. This is consistent with our electrochemical experiment results, which show only one oxidation wave in both dichloromethane and acetonitrle solutions. It is also consistent with our previously reported results on the dinuclear (1) and tetranuclear (3) ferrocene compounds.

Table S2. Selected Bond Lengths $(\AA \AA)$ and Angles (deg) for Compound 2.

\begin{tabular}{cc|lc}
\hline \multicolumn{2}{c|}{ Bond Lengths $(\AA)$} & \multicolumn{2}{c}{ Bond Angles (deg) } \\
\hline $\mathrm{N}(1)-\mathrm{C}(1)$ & $1.464(4)$ & $\mathrm{C}(1)-\mathrm{N}(1)-\mathrm{C}(12)$ & $112.1(2)$ \\
$\mathrm{N}(1)-\mathrm{C}(12)$ & $1.462(4)$ & $\mathrm{C}(1)-\mathrm{N}(1)-\mathrm{C}(23)$ & $113.1(3)$ \\
$\mathrm{N}(1)-\mathrm{C}(23)$ & $1.454(4)$ & $\mathrm{C}(12)-\mathrm{N}(1)-\mathrm{C}(12)$ & $11.7(3)$ \\
\hline
\end{tabular}

\section{PGSE Measurements:}

${ }^{1} \mathrm{H}$ PGSE NMR measurements were performed by using the standard stimulated echo pulse sequence on a Bruker $400 \mathrm{MHz}$ spectrometer at $298.5 \mathrm{~K}$ without spinning. The shape of the gradients was rectangular, their duration $(\delta)$ was $4 \mathrm{~ms}$, and their strength $(G)$ was varied during the experiments. The delay between gradient pulses was $40 \mathrm{~ms}$. All spectra were recorded on a spectrometer equipped with a GAB z-gradient unit capable of producing magnetic pulsed field gradients in the z-direction up to $0.50 \mathrm{~T} / \mathrm{m}$. The semilogarithmic plots of $\ln \left(I / I_{0}\right)$ vs $G^{2}$ were fitted using a Office Excel ${ }^{\odot}$ software; the $R$ factor was always higher than 0.99 . The dependence of the resonance intensity $(I)$ on a constant diffusion time and on a varied gradient strength $(G)$ is described by eq. $S 1$ :

$$
\ln \left(I / I_{0}\right)=-(\gamma \delta)^{2} D(\Delta-\delta / 3) G^{2}
$$

where $I$ is the intensity of the observed spin-echo, $I_{0}$ is the intensity of the spin-echo without gradients, $D$ is the diffusion coefficient, $\Delta$ is the delay between the midpoints of the gradients, $\delta$ is the length of the gradient pulse and $\gamma$ is the gyromagnetic ratio. An 
illustrative example is shown in Figure $\mathrm{S} 1$. The applied gradients were calibrated by measuring the known diffusion coefficient ${ }^{1,2}$ of $\mathrm{HDO}(0.04 \%)$ in $\mathrm{D}_{2} \mathrm{O}$ under the same set of experimental conditions.

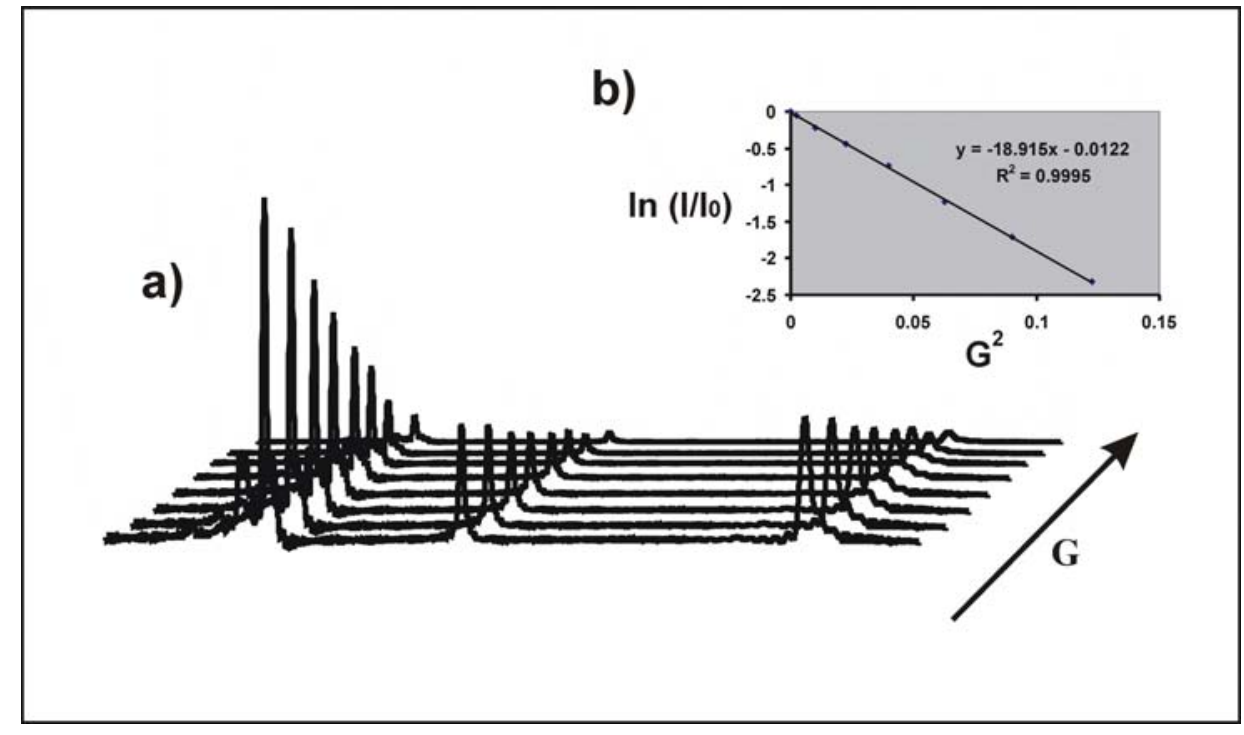

Figure S1. ${ }^{1} \mathrm{H}$ PGSE NMR of compound 3. (a) Stacked plot showing the signal decay as a function of the applied gradient and (b) the corresponding graphical analysis of the data. The diffusion coefficient was measured as $D_{0}=5.76 \times 10^{-6} \mathrm{~cm}^{2} \mathrm{~s}^{-1}$.

\section{References}

1. Mill, R. J. Phys. Chem. 1973, 77, 685.

2. Tyrrell, H. J. W.; Harris, K. R. Diffusion in Liquids; Butterworth: London, 1984. 